\title{
Neuropsychiatric disorders in the 22q11 deletion syndrome
}

Lena Niklasson, $B A^{1}$, Peder Rasmussen, $M D, P h D^{1}$, Sólveig Óskarsdóttir, $M D^{2}$, and Christopher Gillberg, $M D, P h D^{1}$

Purpose: This study was undertaken with a view to establishing the occurrence of neuropsychiatric disorders in the 22q11 deletion syndrome. Methods: Thirty-two children and young adults with genetically confirmed $22 q 11$ deletion were given comprehensive neuropsychiatric assessments. Results: Altogether, 56\% had a neuropsychiatric disorder. Only 6\% were of normal IQ and free of physchiatric disorder. Attention-deficit/hyperactivity disorder was diagnosed in $44 \%$ and $31 \%$ had an autism spectrum problem. In $16 \%$ criteria for both these diagnoses were met. Fifty-three percent had mental retardation, often with a test-profile suggesting a nonverbal learning disorder. Conclusion: The findings imply that a majority of children and adolescents with 22q11 deletion syndrome are in need of neuropsychiatric assessment and intervention. Genetics in Medicine, 2001:3(1):79-84.

Key Words: 22q11 deletion syndrome, attention-deficit/hyperactivity disorder, deficits in attention, motor control, and perception (DAMP), autism, nonverbal learning disorder

The genotype and the physical phenotype of the 22q11 deletion syndrome has been well documented in several publications. There is a high incidence of cardiac malformation, cleft palate, velopharyngeal dysfunction, immune deficiency, and abnormal calcium metabolism, and many individuals with the syndrome show a characteristic combination of minor physical anomalies. ${ }^{1-4}$

A high incidence of relatively mild cognitive deficits, including mild mental retardation (MMR, i.e., IQ 51-70) has recently been documented in this syndrome. One study comprising 37 individuals, aged between 8 months and 20 years, showed an IQ $<70$ in $45 \%$ of cases. ${ }^{5}$ Verbal IQ (VIQ) was significantly higher than performance IQ (PIQ). Moreover, marked problems in social-emotional functioning and attention were common findings.

Severe cognitive deficits, including severe mental retardation (SMR, i.e., IQ <51), appears to be rare in the 22q11 deletion syndrome. ${ }^{6,7} \mathrm{~A}$ few case reports of comorbid autistic disorder/autistic-like condition (pervasive developmental disorders not otherwise specified/PDDNOS) and childhood onset schizophrenia have been published. ${ }^{8}$

Several common behavioral and temperamental features have been noted: impulsiveness and disinhibition on the one hand, shyness and a tendency to withdrawal on the other hand. Some reports suggest that people with the syndrome show a

\footnotetext{
From the ${ }^{1}$ Department of Child and Adolescent Psychiatry, University of Göteborg, Queen Silvia Children's Hospital, Sahlgrenska University Hospital, Göteborg, Sweden; ${ }^{2}$ Department of Pediatrics, Sahlgrenska University Hospital, Queen Silvia Children's Hospital, Göteborg, Sweden.

Lena Niklasson, BA, Department of Child and Adolescent Psychiatry, University of Göteborg, Queen Silvia Children's Hospital, Sahlgrenska University Hospital, Kungsgatan 12, SE-411 19 Göteborg, Sweden.

Received: September 5, 2000.

Accepted: October 12, 2000.
}

characteristic cognitive profile, ${ }^{6,7}$ perhaps even a "behavioral phenotype." Diagnoses such as attention-deficit/hyperactivity disorder (ADHD), attention deficit disorder, emotional instability, and anxiety are reported to be more common than in the general population. ${ }^{9}$

Several authors ${ }^{4,5,7}$ have emphasized that many individuals with 22q11 deletion syndrome have a much higher VIQ than $\mathrm{PIQ}$, suggesting a "right hemisphere syndrome" or "nonverbal learning disorder" (NLD). NLD affects visual-spatial perception, motor skills, nonverbal communication, organization, and often mathematics. Moreover, deficits in social perception, judgment, and interactive skills are often found. ${ }^{10}$ Individuals with NLD may show such severe problems in reciprocal social interaction that an autism spectrum disorder is suspected. ${ }^{11,12}$

The literature referring to adults with the syndrome suggests that there may be a high incidence of psychotic disorders, mainly affective bipolar disorders ${ }^{13}$ and schizophrenia or schizophreniform disorders. ${ }^{14,15}$ Jönsson et al. ${ }^{16}$ reported on a man with 22q11 deletion and recurrent episodes of psychosis of a "schizophrenia-like" kind and a personality suggesting a mild autism spectrum disorder.

Recent estimates of incidence rates of about one in $4000^{17,18}$ suggest that the 22q11 deletion syndrome remains undiagnosed in many individuals, especially in children who have few or no physical abnormalities. There is an impression from clinical work in the field of neuropsychiatry and child neurology that the full spectrum of the syndrome is not yet known, and that 22q11 deletion syndrome may be one of the most common behavioral phenotype syndromes of all.

The present paper is a report from an on-going study of children clinically and genetically diagnosed as having the chromosome 22q11 deletion syndrome. A comprehensive neuropsychiatric assessment, including a detailed neuropsy- 
chological evaluation, of 32 consecutive cases is presented. We believe that the study is helpful in delineating the pattern of neurobehavioral deficits seen in so many individuals with this syndrome. We also want to establish whether there is a correlation between neuropsychiatric disorders and cognitive functioning and, in particular, whether higher VIQ than PIQ plays a role in this respect. Moreover, the results might provide a basis for a better understanding of why and how individuals with this syndrome are sometimes faced with severe psychiatric disorders in adulthood.

\section{Ethics}

The study has been approved by the Ethical Committee of the Medical Faculty, University of Göteborg, Sweden.

\section{MATERIALS AND METHODS}

\section{Subjects}

All the subjects in the present series took part in a comprehensive study of the 22q11 deletion syndrome at the Institute for the Health of Women and Children, Queen Silvia Children's Hospital in Göteborg, Sweden. Various aspects of the syndrome were covered, including cardiologic, immunologic, neurologic and neurodevelopmental, speech and phonologic aspects, ear and hearing, eye and vision, face morphology, odontological aspects, and school situation. The majority of the individuals were referred from the western region of Sweden, but a limited number came from other parts of the country. The results of these studies will be presented separately (Óskarsdóttir et al., in preparation).

The subjects included in the present report were the first 32 children and adults (13 males and 19 females) with a clinical and genetic diagnosis of 22q11 deletion syndrome who underwent assessment at the Child Neuropsychiatric Center at Queen Silvia Children's Hospital. The genetic diagnoses were made by means of fluorescence in situ hybridization for deletions on chromosome 22q11 using the probe $32-19,1028 .{ }^{19}$ The age range of those examined was 5 to 33 years. All the individuals included had the characteristic deletion. Two of the three adults had been diagnosed because they were mothers of children also included in the present study. They showed many characteristic clinical features of the disorder but had not been suspected of having a chromosome abnormality. Fourteen subjects had a congenital cardiac malformation, 10 had a cleft palate (5 of which were of a submucous variety), and 1 had malrotation of the gut. Moreover, there were growth hormone deficit in two subjects and juvenile rheumatoid arthritis, and hypothyroidism in one case each. Two children had cerebral palsy and one had epilepsy. In 26 subjects, there was a history of frequent infections in early childhood.

\section{Methods}

\section{Neuropsychiatric examination}

All examinations were performed at the Child Neuropsychiatric Clinic. The neuropsychiatric evaluation was performed by either of two of the authors (CG, PR) in 26 cases and one of three experienced psychiatrists working in the same department in the remaining six cases. Medical records from the pediatric examinations, performed and summarized by one of the authors $(\mathrm{SO})$, were available in all cases.

Extensive structured and semistructured interview of the parent(s) (the mother in all cases, sometimes the father as well) were performed by the doctor. In the case of adult patients, the probands themselves were interviewed. The interview systematically covered aspects on heredity (first- and second-degree relatives); dwelling conditions and socioeconomic and sociocultural status; medical factors pertaining to pregnancy, parturition, and neonatal period; the child's early psychomotor development and adaptation; physical health problems; further psychomotor and, in particular, speech development; behavior; sustained attention and impulse control; fine and gross motor functions; social interaction skills; eating habits; sleep; bladder and bowel control. Any specific problems suggesting ADHD, Tourette's or obsessive-compulsive disorder, conduct disorder, autism spectrum disorder or any other psychiatric disorder were specifically asked for covering the appropriate DSM-IV criteria. If, after the interview, suspicion in this regard remained, then a highly structured interview covering the symptom criteria of the DSM-IV childhood section was used.

The parent(s) in addition completed the (1) Asperger Syndrome Screening Questionnaire (ASSQ), 20,21 (2) Conners' Brief Parent Questionnaire, ${ }^{22}$ and (3) the Child Behavior Checklist (CBCL), ${ }^{23}$ and a new Nordic questionnaire, currently under development.

The ASSQ yields a range of possible scores of $0-54$. Parent and teacher forms are identical. Agreement across parents and teachers is (unexpectedly) good. ${ }^{21}$ Almost $80 \%$ of children in the general population score 0 on this instrument. Mean general population total score among 7-16 year olds is 0.7 (SD 2.6). Scores of 16 and above on the parent version (used here) yields a likelihood ratio of about 4.5:1 that the child may be suffering from PDDNOS or another autism spectrum disorder. Mean scores for children with ADHD are about 10, whereas mean scores in PDDNOS are about 22. ${ }^{21}$

The Conners scale yields a range of possible scores of $0-30$. Scores of 15 or more are often taken as an indication that the child might be suffering from ADHD.

The CBCL yields a Swedish general population mean total score of 14.3 (SD 12.6). Scores in excess of 57 are associated with child psychiatric "caseness."

The evaluation of the child included a psychiatric assessment (speech and language, social interaction, general intellectual development, sustained attention and activity level, stereotypies, tics, compulsive behavior), a general physical examination (height and weight, head circumference, body constitution and presence of minor physical anomalies, inspection of skin, mouth and throat, auscultation of heart and lungs, palpation of abdomen and lymph glands, and a clinical neurological examination appropriate for the age of the individual, articulation and voice, spontaneous facial expression, position and movements of the eyes, muscular tone including 
assessment for spasticity, tendon reflexes, general posture, balance, gross motor and fine motor coordination).

\section{Neuropsychological assessment}

The neuropsychological assessment was carried out by the same neuropsychologist (LN) in 31 of the 32 cases. The WPPSI-R, ${ }^{24}$ WISC-III, ${ }^{25}$ WAIS-R, ${ }^{26}$ or the Griffiths' Mental Developmental Scales ${ }^{27}$ were used as considered appropriate depending on the individual's age and level of intellectual functioning. Details of further extensive neuropsychological assessments that have been carried out will be described in another paper (Niklasson et al., in preparation). NLD was tentatively considered to be present in cases showing a VIQ over PIQ discrepancy of more than 15\%.

A semistructured behavioral observation of all subjects was performed during the neuropsychologic and psychiatric examinations. This observation covered aspects of attention, activity level and impulse control, social interaction, cooperation, emotional state, speech and language.

\section{Neuropsychiatric diagnostic process}

Comprehensive neuropsychiatric diagnoses were made by the psychiatrist according to the DSM-IV ${ }^{28}$ taking the results of the various examinations (interviews, medical examinations, neuropsychological tests, observations), except those of the CBCL, Conners, and the ASSQ into account. Mental retardation, developmental coordination disorder (DCD), ADHD, and autistic disorder were diagnosed strictly in accordance with the DSM-IV. PDDNOS was diagnosed in cases who either (a) met criteria (or in the case of an adult had done so in the past) for each of the three groups of DSM-IV autism symptoms but with a total of four to five symptoms rather than six or more or (b) whose total score was 6 or more, but full criteria for only two groups of symptoms were met. Diagnoses of mental retardation, DCD, ADHD, autistic disorder/PDDNOS (grouped together as "neuropsychiatric") were not regarded as mutually exclusive. In addition to these neuropsychiatric diagnoses, a number of individuals met criteria for other DSM-IVdiagnoses, such as generalized anxiety disorder and social phobia.

\section{RESULTS}

\section{IQ levels, mental retardation, and NLD}

The mean IQ in the group tested with one of the Wechsler scales $(N=30)$ was 70 . The IQ scores tended to be "normally distributed" around a mean of 70 and a SD of 24.7. Low normal intelligence (IQ 71-85) was found in 10 subjects (31\%). Only five subjects (16\%) had IQ in excess of 85 (Table 1).

Mental retardation (IQ <70) was found in 17 subjects (53\%). Twelve individuals (38\%) had MMR and five (16\%) had SMR.

NLD was tentatively considered to be present in nine cases (VIQ over PIQ superiority of more than 15\%). A reversed pattern was seen in two cases. Only four individuals had a significant difference of $>10$ scaled score points. ${ }^{29}$ In the group tested with the WISC-III $(N=22)$ VIQ was significantly higher than PIQ $(P<0.05)$. In the whole group with IQ measured with one of the Wechsler scales $(N=30)$, VIQ was equal to PIQ in one case, higher than PIQ in 22 cases, and lower in seven cases.

\section{Neuropsychiatric diagnoses}

Twelve individuals (38\%) had no psychiatric diagnosis. However, only two cases in the total group (6\%) were of normal intelligence (IQ in excess of 85) and free from psychiatric disorder. Many subjects showed signs and symptoms of attention deficit (see Table 1). In 14 subjects (44\%) criteria for a diagnosis of ADHD were met. Nine had ADHD, mainly inattention, and five had $\mathrm{ADHD}$, combined type. In five subjects (16\%), there was a combination of ADHD and DCD meaning that they met criteria for the diagnosis of deficits in attention, motor control, and perception (DAMP). ${ }^{30}$ Interestingly, four of these five also showed the NLD pattern. NLD among individuals without DAMP was relatively rare ( 5 of $27, P<0.05$ ). Of the nine individuals with the NLD pattern (see Table 1), four had no neuropsychiatric or general psychiatric diagnosis (however, one of these [case 10 in Table 1] had relatively high scores on all three questionnaires).

Ten individuals $(31 \%)$ were diagnosed as having PDDNOS $(N=9)$ or autistic disorder $(N=1)$. Five of these $(16 \%$ of the total group) also met criteria for ADHD. Fourteen individuals $(44 \%)$ had none of these diagnoses, only two of whom $(6 \%)$ had an IQ above 85 .

Many subjects showed a characteristic combination of marked difficulties in initiating activities and sustaining attention, as if having a general lack of energy (interview data). They were often referred to as "slow performers." Such difficulties were seen in 21 subjects $(66 \%)$, with no difference between those with $(64 \%)$ and those without $(67 \%)$ a diagnosis of ADHD. Three children (two of whom had comorbid diagnoses of PDDNOS, ADHD, and MMR and who had ADHD "only") showed very marked inappropriate anxiety reactions.

In the small group of three adults all had a psychiatric disorder with anxiety as one of the main complaints. All of them had a history of one or more episodes of depression. In two women, DSM-IV criteria for a diagnosis of generalized anxiety disorder were met. In the third case (the only adult who had PDDNOS), criteria for social phobia were met. All three adults had received some kind of psychiatric outpatient treatment, including medication. There were no signs or symptoms of psychotic disorder in any of the subjects.

\section{Behavior problem scores according to the ASSQ, Conners, and the CBCL}

The ASSQ was completed in all cases under age 20 years, except two. The mean score was 14.7 ( $\mathrm{SD}=10.1)$. Twelve individuals had ASSQ score of 16 or more. Nine of these had PDDNOS/autistic disorder (five with comorbid ADHD), one had ADHD "only," and two had no neuropsychiatric diagnosis (but had CBCL-scores not far removed from "caseness"). 
Table 1

Intellectual level (full-scale IQ, verbal IQ, performance IQ), number of symptoms of autism according to the DSM-IV, score on Conners' parent questionnaire, ASSQ, CBCL (see text for explanation), and neuropsychiatric diagnoses (DSM-IV) in 32 individuals with the 22q11 deletion syndrome according to age at assessment and sex

\begin{tabular}{|c|c|c|c|c|c|c|c|c|c|c|}
\hline \multirow[b]{2}{*}{ Case } & \multirow[b]{2}{*}{ Age } & \multirow[b]{2}{*}{ Sex } & \multicolumn{3}{|c|}{ Intellectual level } & \multirow{2}{*}{$\begin{array}{l}\text { Autism symptoms } \\
\text { DSM-IV }\end{array}$} & \multirow{2}{*}{$\begin{array}{l}\text { Conners' } \\
\text { score }\end{array}$} & \multirow{2}{*}{$\begin{array}{c}\text { ASSQ } \\
\text { score }\end{array}$} & \multirow{2}{*}{$\begin{array}{l}\text { CBCL } \\
\text { score }\end{array}$} & \multirow{2}{*}{$\begin{array}{c}\text { Neuropsychiatric disorder current } \\
\text { (not MMR or SMR) }\end{array}$} \\
\hline & & & FSIQ & VIQ & PIQ & & & & & \\
\hline 1 & $5: 3$ & $\mathrm{~F}$ & \multicolumn{3}{|c|}{ Griffiths, MMR } & $5(2,2,1)$ & 11 & 39 & 64 & PDDNOS, ADHD \\
\hline 3 & $5: 8$ & $\mathrm{~F}$ & 84 & 81 & 91 & $0(0,0,0)$ & 0 & 3 & 19 & - \\
\hline 4 & $5: 10$ & $\mathrm{~F}$ & 71 & 75 & 72 & $5(2,2,1)$ & 24 & 23 & 72 & PDDNOS, ADHD \\
\hline 6 & $7: 0$ & $\mathrm{~F}$ & 57 & 53 & 69 & $8(2,4,2)$ & 10 & 22 & 79 & Autistic disorder, ADHD \\
\hline 7 & $7: 3$ & M & 66 & 74 & 64 & $3(2,0,1)$ & 27 & 33 & 111 & $\mathrm{ADHD}, \mathrm{DCD}^{*}$ \\
\hline 8 & $7: 7$ & $\mathrm{~F}$ & 91 & 92 & 91 & $0(0,0,0)$ & 4 & 5 & 16 & - \\
\hline 9 & $7: 8$ & $\mathrm{~F}$ & 73 & 86 & 66 & $1(1,0,0)$ & 9 & 10 & 38 & $一^{*}$ \\
\hline 13 & $8: 7$ & $\mathrm{~F}$ & 75 & 86 & 70 & $2(2,0,0)$ & 4 & 3 & 44 & - $^{*}$ \\
\hline 14 & $10: 2$ & M & 65 & 69 & 62 & $4(2,0,2)$ & 15 & 6 & 58 & $\mathrm{ADHD}, \mathrm{CP}$ \\
\hline 15 & $11: 4$ & $\mathrm{~F}$ & 86 & 91 & 84 & $0(0,0,0)$ & 7 & 13 & $\mathrm{md}$ & ADHD \\
\hline 16 & $11: 4$ & M & 76 & 84 & 73 & $0(0,0,0)$ & 4 & 0 & 32 & $一^{*}$ \\
\hline 17 & $11: 5$ & M & 79 & 84 & 78 & $2(1,0,1)$ & 16 & 13 & 38 & ADHD \\
\hline 18 & $12: 5$ & $\mathrm{~F}$ & 67 & 68 & 71 & $1(0,1,0)$ & 8 & 25 & 45 & - \\
\hline 19 & $12: 6$ & M & 46 & 54 & 47 & $5(3,2,0)$ & 17 & 20 & 52 & PDDNOS, ADHD \\
\hline 20 & $12: 9$ & $\mathrm{~F}$ & 78 & 87 & 74 & $1(0,0,1)$ & 4 & 11 & 34 & $\mathrm{ADHD}, \mathrm{DCD}^{*}$ \\
\hline 27 & $16: 3$ & M & 61 & 58 & 57 & $2(1,1,0)$ & 3 & 9 & 15 & - \\
\hline 28 & $17: 3$ & M & 54 & 59 & 56 & $4(2,1,1)$ & 10 & 9 & 18 & PDDNOS \\
\hline 29 & $17: 3$ & M & 83 & 91 & 76 & $2(1,1,0)$ & md & md & md & $\mathrm{ADHD}, \mathrm{DCD}^{*}$ \\
\hline 30 & 19:11 & $\mathrm{F}$ & 100 & 94 & 105 & $4(3,0,1)$ & 23 & 27 & $\mathrm{md}$ & ADHD, Generalized anxiety \\
\hline 31 & $29: 3$ & $\mathrm{~F}$ & 73 & 78 & 70 & $4(2,1,1)$ & $\mathrm{md}$ & md & $\mathrm{md}$ & PDDNOS \\
\hline 32 & $33: 7$ & $\mathrm{~F}$ & 76 & 84 & 73 & $2(1,0,1)$ & md & $\mathrm{md}$ & md & Generalized anxiety* \\
\hline
\end{tabular}

Age at assessment given in years:months; F, female; M, male; in cases 1 and 5, intellectual level refers to the developmental quotient according to Griffiths' Mental Developmental Scales (MMR, mild mental retardation; SMR, severe mental retardation). FSIQ, full-scale IQ; VIQ, verbal IQ; PIQ, performance IQ. ADHD, attention-deficit/hyperactivity disorder; PDDNOS, pervasive developmental disorder not otherwise specified; DCD, developmental coordination disorder; CP, cerebral palsy; md, missing data.

* VIQ more than 15\% greater than PIQ tentatively indicating NLD. Autism symptoms (range 0-12; social, communication, behavior symptoms in brackets).

The Conners scale was completed in all cases under age 20 years, except one. The mean score was $10.8(\mathrm{SD}=7.0)$. Eight individuals had Conners scores of 15 or more. Seven of these had ADHD (three with comorbid PDDNOS) and one had PDDNOS “only."
The CBCL was completed in 26 of the 29 children under age 18 years. The "total problem score" was significantly higher in this group than in the Swedish norm group. The mean score was $45.6(\mathrm{SD}=24.9)$ as compared with $14.3(\mathrm{SD}=12.6)$ in the recently examined Swedish norm group $(P<0.01)$. Eight in- 
dividuals had CBCL scores of 58 or more, indicating "caseness." Six of these had PDDNOS/autistic disorder, with $(N=$ $4)$ or without $(N=2)$ comorbid ADHD, and two had ADHD "only."

\section{Neuropsychiatric diagnoses according to IQ}

Individuals with no neuropsychiatric diagnosis had a mean IQ of $70(N=13)$. In the group with a diagnosis of ADHD without PDDNOS/autistic disorder $(N=11)$ mean IQ was 73 . In the group with a diagnosis of ADHD with PDDNOS/autistic disorder $(N=5)$, mean IQ was 61 , and in the group with PDDNOS “only," mean IQ was 55.

In the group of nine individuals, who had a VIQ superiority of more than 15\%, three had ADHD, two had a combination of ADHD and PDDNOS, and four individuals had no neuropsychiatric diagnosis. In the two individuals with a corresponding PIQ superiority, one had autistic disorder and ADHD and the other one had no diagnosis. Five individuals in the whole group had a combination of ADHD and DCD (DAMP). Four of them had a VIQ superiority of $>15 \%$.

\section{Schooling}

Eight of the nine school-aged children who had normal or low normal intelligence had marked learning and/or behavioral difficulties in school. They had at least part-time support by an assistant, or they attended a small group with extra resources.

\section{DISCUSSION}

Only $13 \%$ of the present study group had no psychiatric/ neuropsychiatric diagnosis, i.e., they were of normal or low normal intelligence and did not have ADHD, autistic disorder, PDDNOS or another major psychiatric disorder. Conclusions based on the present findings need to be tempered by the fact that this was not a population-based sample and that the study group was relatively small. Even so, the finding that the vast majority of the individuals with 22q11 deletion syndrome had neuropsychiatric disorders is of considerable clinical importance. With the exception of four subjects who were originally referred for neuropsychiatric assessment (with a deletion syndrome previously not suspected) they had not been selected for examination due to neurobehavioral or learning deficits.

A high prevalence of MMR in individuals with a 22q11 deletion has been documented in several other studies. In this series, it appeared that the distribution of IQ resembles a normal distribution with a mean of 70 and a range of $40-100$. A statistically significant VIQ over PIQ superiority was documented in the present study, as in other studies. ${ }^{6,5,9,31}$ The difference was mostly small, but in nine cases, it was so pronounced that NLD (suggesting right hemisphere dysfunction) was inferred. ${ }^{10}$

Attention deficits have also been described as a common trait in the $22 \mathrm{q} 11$ deletion syndrome. ${ }^{2}$ In the present study, ADHD - always "mainly inattentive" or "combined," never "mainly hyperactive-impulsive" - was diagnosed in more than two in five of all subjects. Attention deficit problems were also clearly supported by findings on the Conners and CBCL rating scales. A subgroup ( $16 \%$ of all cases) had ADHD with comorbid DCD, a combination referred to in the Nordic countries as DAMP. The majority of the children in this subgroup also fitted the NLD criteria tentatively employed.

No previous study of the 22q11 deletion syndrome has reported a similarly high rate of autism spectrum disorders. Three in ten of the individuals in the present study had PDDNOS, including autistic disorder in one case. A full $72 \%$ had at least one of the social impairment symptoms of autism. The mean ASSQ score was in between that reported for ADHD and PDDNOS. ${ }^{21}$ Social impairment is very common in the NLD syndrome, but there was no clear correlation between presence or degree of autistic type social impairment and the diagnostic category of NLD as used in the present context. Nevertheless, both the attention deficits and the autistic type symptomatology encountered in so many of the cases examined in this study are reminiscent of the kind of clinical problems described in children with NLD. ${ }^{10}$

Perhaps the most specific neurobehavioral problem identified in this study was one that does not fit with any of the currently used diagnostic systems. According to interview data, many of the subjects had a characteristic combination of marked difficulties in starting or initiating activities, a deficit in sustaining attention and a slow performance-a "lack of mental energy." Again, this clinical presentation is similar to that described in NLD. A few of the children in the study were also reported to have anxiety reactions that were much more prominent than could be accounted for by their having ADHD or PDDNOS. As mentioned before, the majority of the children showed considerable difficulties in social interaction. The presence of limited facial expression and speech problems, occurring in many of these individuals, may play a contributory role in this respect.

All the three adults in this presentation had some kind of psychiatric disorder with severe anxiety as a main complaint. At age 20-34 years, they had no signs or symptoms of schizophrenia or bipolar disorder. One of these three had a history of PDDNOS, but no longer met criteria for disorder in this domain. The adult subgroup is much too small for meaningful conclusions, but it is possible that ADHD and PDDNOS in childhood may be "followed" by severe anxiety disorder in early adult age in this particular patient group.

In summary, this study shows ADHD and PDDNOS to be very common in $22 \mathrm{q} 11$ deletion syndrome. It is possible that there is considerable overlap between these diagnostic categories and NLD in this patient group, but the present study did not find unequivocal support for such an association. Both ADHD and PDDNOS are considered important psychiatric problems and both are amenable to interventions of various kinds. Children with 22qll deletion syndrome are in need of neuropsychiatric assessment and therapy in a vast majority of all cases. Neuropsychiatric evaluation should be included in future research studies of the condition. 


\section{References}

1. Shprintzen RJ, Goldberg RB, Lewin ML, Sidoti EJ, Berkman MD, Argamaso RV Young D. A new syndrome involving cleft palate, cardiac anomalies, typical facies and learning disabilities: velo-cardio-facial syndrome. Cleft Palate Journal 1978;15: $56-62$.

2. Goldberg R, Motzkin B, Marion R, Scambler PJ, Shprintzen RJ. Velo-cardio-facial syndrome: a review of 120 patients. Am J Med Genet 1993;45:313-319.

3. Thomas JA, Graham JM Jr. Chromosome 22q11 deletion syndrome. An update and review for the primary pediatrician. Clin Pediatr (Phila) 1997;36:253-266.

4. McDonald-McGinn DM, Kirschner R, Goldmuntz E, Sullivan K, Eicher P, Gerdes M, Moss E, Solot C, Wang P, Jacobs I, Handler S, Knightly C, Heher K, Wilson M, Ming JE, Grace K, Driscoll D, Pasquariello P, Randall P, Larossa D, Emanuel BS, Zackai EH. The Philadelphia story: the 22q11 deletion: report on 250 patients. Genet Couns 1999;10:11-24.

5. Swillen A, Devriendt K, Legius E, Fryns JP. Intelligence and psychosocial adjustment in velocardiofacial syndrome: a study of 37 children and adolescents with VCFS. J Med Genet 1997;34:453-458.

6. Golding-Kushner KJ, Weller G, Shprintzen RJ. Velo-cardio-facial syndrome: language and psychological profiles. J Craniofac Genet Dev Biol 1985;5:259-266.

7. Swillen A, Devriendt K, Legius E, Prinzie P, Vogels A, Chesquierer P, Fryns JP. The behavioral phenotype in Velo-cardio-facial syndrome (VCFS): from infancy to adolescence. Genet Couns 1999;10:79-88.

8. Usiskin S, Nicolson R, Krasnewich D, Yan W, Lenane M, Wudarsky M, Hamburger S, Rapoport J. Velocardiofacial syndrome in childhood-onset schizophrenia. J Acad Child Adolesc Psychiatry 1999;38:1536-1543.

9. Gerdes M, Solot C, Wang PP, Moss E, LaRossa D, Randall P, Goldmuntz E, Clark BJ 3rd, Driscoll DA, Jawad A, Emanuel BS, McDonald-McGinn DM, Batshaw ML, Zackai EH. Cognitive and behavior profile of preschool children with chromosome 22q11.2 deletion. Am J Med Genet 1999;85:127-133.

10. Rourke BP. The syndrome of nonverbal learning disabled children: developmental manifestation of neurological disease. Clin Neuropsychol 1988;2:293-330.

11. Klin A, Volkmar S, Sparrow D, Cicchetti D, Rourke B. Validity and neuropsychological characterization of Asperger syndrome: convergence with nonverbal learning disabilities syndrome. J Child Psychol Psychiatr 1995:36:1127-1140.

12. Gross-Tsur V, Shalev R, Manor O, Amir N. Developmental right-hemisphere syndrome: clinical spectrum of the nonverbal learning disability. J Learn Disabil 1995; 28:80-86.

13. Papolos DF, Faedda GL, Veit S, Goldberg R, Morrow B, Kucherlapati R, Shprintzen RJ. Bipolar spectrum disorders in patients diagnosed with Velo-cardio-facial syndrome: does a hemizygous deletion of chromosome 22q11 result in bipolar affective disorder? Am J Psychiatry 1996;15:1541-1547.
14. Bassett A, Hodgkinson K, Chow E, Correia S, Scutt L, Weksberg R. 22q11 deletion syndrome in adults with schizophrenia. Am J Med Genet 1998;81:328-337.

15. Murphy KC, Jones LA, Owen MJ. High rates of schizophrenia in adults with Velocardio-facial syndrome. Arch Gen Psychiatry 1999;56:940-945.

16. Jönsson S, Björkman A, Schultz L, Kristoffersson U. High risk of psychosis in VeloCardio-Facial syndrome-a case report (in Swedish). Lakartidningen 1997:94:329 331.

17. Devriendt K, Fryns JP, Mortier G, van Thienen MN, Keymolen K. The annual incidence of DiGeorge/Velocardiofacial syndrome. J Med Genet 1998;35:789-790.

18. Óskarsdóttir S, Fasth A, Belfrage M, Viggedal G, Persson C, Eriksson BO. CATCH 22-syndrome: an underdiagnosed and misinterpreted disorder with varying signs and symptoms (in Swedish). Lakartidningen 1999;96:4789-4793.

19. Dallapiccola B, Pizzuti A, Novelli G. How many breaks do we need to CATCH on 22q11? Am J Hum Genet 1996;59:7-11.

20. Ehlers S, Gillberg C. The epidemiology of Asperger syndrome. A total population study. J Child Psychol Psychiatry 1993;34:1327-1350.

21. Ehlers S, Gillberg C, Wing L. A screening questionnaire for Asperger syndrome and other high-functioning autism spectrum disorder in school age children. J Autism Dev Disord 1999;29:129-141.

22. Conners CK. Conners rating scales manual, Conners teacher rating scales, Conners parent rating scales. Instruments for use with children and adolescents. North Tonawanda, N.Y.: Multihealth Systems, 1990

23. Achenbach TM. Manual for the Child Behavior Checklist/4-18 and 1991 profile. Burlington, VT: University of Vermont Department of Psychiatry, 1991.

24. Wechsler D. Wechsler preschool and primary scale of intelligence-revised. New York: Psychological Corporation, 1989.

25. Wechsler D. Manual of the Wechsler intelligence scale for children. 3rd ed. New York: Psychological Corporation, 1992

26. Wechsler D. Manual of the Wechsler adult intelligence scale-revised. San Antonio: Psychological Corporation, 1981.

27. Griffiths R. The abilities of young children. A study in mental measurement. London: University of London Press, 1970.

28. American Psychiatric Association. Diagnostic and statistical manual of mental disorders. 4th ed. Washington, DC: American Psychiatric Association, 1994.

29. Kaufman A. Intelligence testing with the WISC III. New York: John Wiley \& Sons, Inc., 1994.

30. Kadesjö B, Gillberg C. Attention deficits and clumsiness in Swedish 7-year-old children. Dev Med Child Neurol 1998;40:796-804.

31. Wang P, Woodin M, Kreps-Falk R, Moss E. Research on behavioral phenotypes: velocardiofacial syndrome (deletion 22q11.2). Dev Med Child Neurol 2000;42:422427. 